\title{
THE EMOTIONS OF THE ANCIENT GREEKS: A CROSS-CULTURAL PERSPECTIVE
}

\author{
David KONSTAN ${ }^{1)}$ \\ ${ }^{1)}$ Brown University, U.S.A.
}

\begin{abstract}
This paper presents a survey of the emotions of the ancient Greeks, as defined and illustrated by Aristotle, and offers a systematic comparison with emotions as conceived today. The object is to exhibit the differences between the ancient and modern classifications, and to indicate some areas where the classical interpretation can shed light on contemporary issues in the psychology of the emotions.
\end{abstract}

Key words: emotion, Greece, comparative psychology, social constructionism

That there are broad similarities in the range and nature of emotions across cultures is clear enough; equally certain is the fact that particular terms for emotions in one culture do not necessarily map exactly onto those in another. What is more, the differences may be systematic, in the sense that, taken together, both the inventory of basic emotion terms in a culture, and the specific character of the several emotions included, may reveal a coherent structure of feeling that differs in determinate ways from that of other cultures (for cross-cultural approaches to the emotions, see Abu-Lughod, 1999; Casimire \& Schnegg, 2003; Lutz, 1988). Finally, the entire system may be seen to bear a relationship to values and beliefs within the culture at large, which is in turn distinctive in respect to that of other societies.

\section{THEORETICAL CONTEXT}

There is, of course, a school of thought that holds that emotions are universal, in which case cross-cultural comparisons are otiose. Charles Darwin's last book, The Expression of the Emotions in Man and Animals (1872; rev. ed. 1998), related the emotional life of human beings to that of the more primitive species from which mankind had evolved. Darwin supposed that certain expressive features in humans are as innate and universal as snarling is to dogs. So too, the human smile and other expressive behaviors were treated by Darwin as invariants over different populations and cultures: "With all the races of man the expression of good spirits appears to be the same, and is easily recognized" (Darwin, 1998, p. 211). Darwin confirmed his hypotheses by examining descriptions of human responses drawn from different cultures, particularly those that he and his contemporaries regarded as primitive.

Correspondence concerning this article should be addressed to David Konstan, Department of Classics, Brown University, Providence, RI 02912-1856, U.S.A. (e-mail: David_Konstan@brown.edu). 
Over the past thirty years, Paul Ekman and his associates have continued Darwin's work, developing experiments designed to demonstrate that the basic emotions are universally recognized from facial expressions, irrespective of differences in language and culture. Ekman has used more refined techniques than Darwin did, taking larger population samples, making the questionnaires more objective, and employing the results of carefully controlled laboratory experiments. Ekman found it practical to reduce Darwin's large range of emotions to a few basic ones which could be readily discriminated: anger, disgust, sadness, enjoyment, fear and surprise (the two last sometimes conflated into one) are his primary categories, although he suggests as well that contempt and perhaps the complex of shame and guilt have universal expressions (Ekman, 1998, pp. 390-391). Ekman remarks, however, that "Jealousy seems to have no distinctive expression."

The new discipline of evolutionary psychology, also indebted to Darwin, has again assumed that emotions are innate and universal. Both love and jealousy, for example, are identified as basic emotions by David Buss, who affirms that "People in all cultures experience love and have coined specific words for it" (1994, p. 2). Love is interpreted as an element of mating strategies; Buss explains, for example, that "men and elephant seals share a key characteristic: both must compete to attract females" (p. 9). The competition to attract has as its complement the struggle to retain the partner once she (the gender of the pronoun is significant) has been won: "Male sexual jealousy evolved as a psychological strategy to protect men's certainty of their paternity" (Buss, 2000, p. 16). Buss does not make clear what the evolutionary advantage of such knowledge might be. More importantly, however, Buss's explanation takes it for granted that jealousy is in fact universal. But just that has to be demonstrated (on the problem of jealousy in ancient Greek culture, see Konstan, 2003a; on jealousy in general, see Farrell, 1989).

The linguist Anna Wierzbicka has mounted the most direct and forceful attack on Ekman's project. Wierzbicka (1999, p. 168) cites Ekman's claim (1980, pp. 137-138) that "Regardless of the language, of whether the culture is Western or Eastern, industrialized or preliterate, these facial expressions are labelled with the same emotion terms: happiness, sadness, anger, fear, disgust and surprise," and points out that these labels are hardly indifferent to language. As Wierzbicka puts it, Ekman "continues to imply that these 'discrete phenomena' can be identified by means of English lexical categories such as'anger' or 'sadness.' From this perspective, English lexical categories such as 'sadness' or 'anger' appear to cut nature at its joints ..., whereas the lexical categories of languages like Ifaluk or Pintupi ... can only correspond to 'blends." "The result is that Ekman and his colleagues "absolutize the English folk-taxonomy of emotions" (p. 171).

No one denies that the human face has a variety of expressions, or that some gestures may have natural limits: one can only raise the corners of the mouth so far in smiling, or depress them so far to cause a frown. There are data to "suggest that even very young infants ... are able to discriminate the features of the face that to an adult denote facial expressions" (Nelson \& de Haan, 1997, p. 183; cf. p. 198). But why treat acute gestures as indices of basic or elementary emotions? Extreme cases, as Aaron Ben-Ze'ev (2000, p. 8) 
remarks, "are mistakenly perceived to be both typical and frequent because ... they are more noticeable."

Ekman's Darwinian approach is vulnerable also to the criticism that the information communicated by facial and other gestures is not as consistent as his research method might lead one to believe. Russell (1997, p. 312) observes, for example, that in experiments in which photographs were combined with stories, "In every case, the modal emotion chosen coincided with the prediction based on the situation rather than on the face." An additional factor is facial mobility. As Bavelas and Chovil (1997, p. 339) point out, "faces in dialogue move rapidly to convey meaning in conjunction with other, simultaneous symbolic acts." There is ample reason, then, to suppose that even on the terrain of the expression of the emotions, cultural conditioning plays a major role in how they are constructed, experienced, and communicated.

Expression, however, is only the final phase of the emotional process. Where cultural variation might be expected to play a larger role is in the stimulus or cause of an emotion, which is evaluated cognitively. Over the past thirty years or so, investigators in several disciplines have increasingly recognized that emotions typically involve a substantial cognitive and evaluative component (see Averill 1980; Frank, 1988; Harré, 1986; Oatley, 1992; Rorty, 1980; Solomon, 1993; on appraisal, Forgas, 2000; Frijda, 1993; Frijda, Manstead, \& Bem, 2000; Scherer, Schorr, \& Johnstone, 2001). The traditional opposition between reason and emotion is no longer the reigning paradigm in science or philosophy. William Lyons (1980, p. 70), for example, defines an emotion as consisting of cognitive (or perceptual), evaluative, and appetitive elements, and observes that what differentiates one emotion from another is precisely the evaluative part. Some theorists, in fact, have interpreted emotions as nothing more than judgments - albeit judgments of a particular kind, so as to distinguish them from other cognitive activities (Lazarus, 1991, p. 353; Nussbaum, 2001; Solomon, 1993, pp. viii, 125-126). What is more, an emphasis on cognition and appraisal is fully present in ancient Greek accounts of the emotions. As Richard Lazarus, one of the founders of modern appraisal theory, observes (2001, p. 40; cf. Hinton, 1999, p. 6), "those who favor a cognitive-mediational approach must also recognize that Aristotle's Rhetoric more than two thousand years ago applied this kind of approach to a number of emotions in terms that seem remarkably modern." Thus, the chasm that seems to divide the cognitivist view and that of the neoDarwinists may be in large measure a consequence of focusing on distinct moments in the emotional process.

\section{Aristotle ANd AnCient Greek Emotions}

The test of a comparative approach to emotion is the extent to which it is helpful in defining the emotional organization of a specific culture, and by doing so helps to shed light on other emotional regimes with which it may be compared. In what follows, I propose to examine a set of emotions that can reasonably be taken to be basic to ancient Greek culture at what many consider its apogee, that is, classical Athens of the fifth and 
fourth centuries B.C. There is an obvious drawback to undertaking such an investigation: the culture is long since extinct, and there are no native speakers to inform us of the meanings of their emotional vocabulary. There are, in turn, several important advantages, which make the project both feasible and informative. First, the Greeks left a rich written literature, including fiction, courtroom speeches, historical accounts, and poetry, which permits us to see their emotional repertoire in action. Second, and more relevant to the present study, they also produced careful definitions and descriptions of the basic emotions, of which the most extensive and rigorous for the epoch under consideration is that of Aristotle, no mean thinker. Of course, philosophers may have their particular angle, which can distort the descriptions they provide. But there are good reasons to trust Aristotle's account more than that of some other systematic thinkers. For one thing, he was of a practical cast of mind, more interested in things as they were (for example, classifying plants and animals) than projecting ideal types. In addition, his treatment of the emotions, like that of many writers in classical antiquity, is to be found not in his treatises on the soul (psychology in the ancient sense) but in his essay on rhetoric, since orators were expected to know how to rouse or assuage the emotions of their audiences. To be effective, such an analysis must take into account the emotions of the ordinary people who made up the juries and assemblies of ancient Athens - that is to say, all free adult males in the population (this restriction of course limits the applicability of the Greek model to modern societies). Lastly, it is the case that classical Greece is still understood by many to be the foundation of modern western culture. This is at best a partial truth, but given Greece's privileged status in the ideology of the so-called west, and the tendency to assume that its values and sensibilities correspond neatly to those prevailing in Europe and America today, it is worth examining their attitudes with some precision to determine just how far the resemblances hold, and what the differences may signify. It is remarkable that relatively little work has been done on this subject to date (but see Allen, 1999; Barton, 2001; Braund \& Most 2003; Cairns, 1993; Dover, 1994; Fortenbaugh, 2002; Harris, 2001; Kaster, 1997; Kaster, 2005; Konstan \& Rutter, 2003; Rorty, 1996; Rosenwein, 1998; Sorabji, 2000; Toohey, 2004).

In what follows, I present the several emotions that Aristotle singles out for analysis in his Rhetoric (Book 2, chapters 1-11), and a brief account of his definitions and their most salient features (translations in Roberts, 1984; Kennedy, 1991). Ideally, one would then see to what extent Aristotle's interpretations square with the use of these and other emotion terms in contemporary Greek literature. Such a study, however, exceeds the scope of this paper, though I have undertaken it elsewhere (see especially Konstan, 2006). But Aristotle alone will provide sufficient material, and in general it can be supported from other texts as well.

\section{Anger and its Opposite}

The first emotion that Aristotle treats in the Rhetoric (Book 2, chapter 2) is usually translated as "anger." This is a reasonable approximation, but even a cursory examination of his definition and description reveals significant differences between the Greek orgê the term Aristotle subjects to analysis — and the English "anger." Here, then, is 
Aristotle's definition: "let anger [orgê] be a desire, accompanied by pain, for a perceived revenge, on account of a perceived slight on the part of people who are not fit to slight one or one's own." The reference to pain is due in part to Aristotle's definition of emotion (his word is pathos) in the first chapter of Book 2: "Let the emotions be all those things on account of which people change their minds and differ in regard to their judgments, and upon which attend pain and pleasure, for example anger, pity, fear, and all other such things and their opposites." One might see in the mention of pain and pleasure an anticipation of the modern notion that emotions have positive and negative valence, but this is not strictly the case, for Aristotle sees at least some and perhaps all emotions as involving both sensations. Thus, in the case of anger, the pleasure derives from the expectation or anticipation of revenge, which is why we often nourish anger. Now, there are several remarkable features in Aristotle's definition of anger: for example, that anger is basically a desire for revenge; that this desire is provoked by a slight or belittlement and only that; and that some people, but only some, are not fit to slight another. We may note too that evaluation or appraisal is central to Aristotle's approach. A slight is a complex social event, and it requires a complex judgment to recognize it; among other things, one must be aware of social roles, in order to know who is and is not fit to offer insult. What is more, anger cannot, on this description, be aroused by inanimate objects, since they are not capable of offering a slight, nor is it possible to take revenge on them ${ }^{1}$.

We have seen that Aristotle limits the causes of anger to intentional offenses of a single kind, summed up by the term "slight," although modern English speakers are inclined to identify a wider range of causes of anger, including such stimuli as frustration, noise, and crowds (Tavris, 1989, pp. 164-177). What, then, is a slight? Aristotle defines it as "the active belief that something seems worthless." To see how severe a restriction this is, consider the three classes of slight that Aristotle enumerates. The first is contempt, which he defines as the belief that a thing is of no value. The second category is "spite," which Aristotle defines as "blocking the wishes of another not in order to have something for oneself but rather so that the other not have it." In this case, the slight, Aristotle explains, lies precisely in that the offender seeks no personal advantage: the only explanation for such a gratuitous hindrance of another's wishes, according to Aristotle, is that one neither fears him nor seeks his friendship; he is thus useless whether for good or ill, which is just what it is to be worthless. If the motive were self-interest (e.g., blocking an investment profitable to another that would damage one's own portfolio), it would not be a clear case of belittlement, since one can impede another person's plans out of selfishness and still respect him or her. And if that were the case, then the act, according to Aristotle, would not produce anger, for anger results from a slight and nothing else.

So too with Aristotle's third category of slighting, namely hubris or arrogant abuse,

\footnotetext{
${ }^{1}$ We may wonder, then, what Aristotle supposed we feel when we strike a chair in irritation after stubbing our toe against it. Aristotle does not provide a precise answer, but we may sketch in a couple of possible acounts on his behalf: either (1) we personify the chair and imagine it feels humiliated by our action (and thus that we have avenged its insolence), or (2) we strike out in a blind reaction that is not so much an emotion as a reflex. Some ancient philosophers (for example, the Stoic Seneca) recognized such automatic responses, and labelled them "pre-emotions."
} 
which is defined as speaking or acting in ways that cause shame to another, not so that something may happen to you or because something has happened, but for the sheer pleasure of it. If the abuse is in return for an injury, it does not count as insolence but rather as revenge. The kind of affront that provokes anger, Aristotle explains, must be neither in reprisal for an offense nor beneficial to the offender, but purely a function of arrogance - that is, a form of belittlement.

It is evident that the causes of anger, in Aristotle's view, are far more limited than English speakers suppose. For example, anger is not a response to harm as such, even when the harm is intentional. To see how different Aristotle's anger is from our own, let me offer some illustrations. Aristotle points out that no one slights a person he fears (2.3, 1380a22-23), because fear is a sign of one's own weakness, and this is incompatible with contempt for the other. Of course, we can certainly hate such a person, and normally do. As Aristotle says, "no one likes [philei] a person he fears" (I return to hatred below). For the same reason we are not angry with those who fear us, since their fear demonstrates their respect for us (hence, they cannot slight us), though we may certainly dislike them. What is more, Aristotle says that "it is impossible to be afraid of and angry with someone at the same time." The reason why, it seems clear, is that we acknowledge by our fear the superior status of the other, who is accordingly in a fit position to deliver a slight. Nor can we return anger for anger, according to Aristotle, since those who are angry at us do not appear to act out of contempt, but are responding precisely to our disdain for them. The result of a slight is that we find ourselves diminished in esteem, whether in our own eyes or those of others, and in order to turn the tables on the offender, we must first restore the original equilibrium through an act of revenge. Until that happens, we are not in a position to diminish the other, and hence inspire her or his anger.

The role of status in Aristotle's conception of anger is evident. Even so, and despite the initial strangeness of his account, I have found that it often serves to illuminate or expose the actual sentiments that lie behind anger today. It is not my purpose here to advocate the application of Aristotle's analyses to modern emotions, and so I leave this question to another occasion, or to the readers of this journal, and proceed to the other emotions Aristotle discusses.

The second emotion that Aristotle examines is what he identifies as the opposite of anger (we have seen in his definition of emotion that he is disposed to see emotions as coming in contrasting pairs). Most often, his term, praünsis, is translated as "calming down" or the like. His definition runs: "Let praünsis be a settling down and quieting of anger. If, then, people are angry at those who slight them, and a slight is a voluntary thing, it is clear that people are praoi ("calm" or "gentle") in turn toward those who do no such things or do them involuntarily or who seem like that" (2.3). Now, this would seem more like the appeasement or allaying of an emotion than an emotion proper, and so most scholars have interpreted it. But Aristotle at least suggests that people who are serious or eager about something tend to be praoi toward those who are similarly disposed, for they believe that they themselves are being taken seriously and not being treated with contempt; this looks like a response to respectful comportment per se. So too, we are praoi toward those who have obliged us, or begged and pleaded with us, since they are 
humbler; or again, toward those who are never arrogant or insulting toward people like ourselves. In these instances, we are praoi just because of the consideration, or rather the deference, of others, and not necessarily because of some supposed appeasement. So the opposite of anger is elicited, it would appear, by admiration or other signs of humility or self-abasement that elevate our standing or esteem.

Such an account is not wholly surprising in the context of Aristotle's analysis of anger. If anger is a response to a slight, as Aristotle holds, and if, moreover a slight is a belief that something is worthless, then the opposite of anger should or at least could be a response to the belief that one is of some value. The corresponding emotion would derive from the sense of an increase in one's status: we might perhaps think of it as the sense of satisfaction that results from praise or some other act that enhances a belief in one's own worth (see Konstan, 2003b).

\section{Love and Hate}

Aristotle now turns to the emotions of love and hate, which he treats in Chapter 4. He defines the verbal idea, "to love" (his word is philein) as follows: "Let loving be wishing for someone the things that he deems good, for the sake of that person and not oneself, and the accomplishment of these things to the best of one's ability." Love, then, is an altruistic sentiment in regard to another that includes the desire or intention to provide the other with what she or he values. No other conditions for loving are specified: nothing is said, for example, about duty or obligation. As far as the performance of services is concerned, loving just consists in the uncoerced wish to provide them. Here, then, there is no tension between the sentiment of love and the requirement that one help others to achieve the goods to which they aspire. For if loving as an emotion just is the wish to provide such assistance, then the failure to aid another convicts one of a want of love. That love resides in an active wish to provide good things for another gives a special cast to these concepts in Greek. The second edition of Webster's New International Dictionary (1961, p. 1462) defines "love" as "a feeling of strong personal attachment" and "ardent affection." So too, in a recent handbook on emotion, Elaine Hatfield and Richard Rapson (2000, pp. 654-655) distinguish "passionate" and "companionate" love, and of the latter they write: "It combines feelings of deep attachment, commitment, and intimacy." Aristotle says nothing about feelings or attachment; he mentions only a benevolent intent or concern for the well-being of another, which manifests itself in actions. Rather than focus on interior states, Aristotle typically attends to the social motives and consequences of the emotions.

So too, Aristotle carefully notes the personal qualities in others that elicit our love and benevolence. An emotion for Aristotle is characteristically a reaction to the merits and intentions of others (the word pathos is etymologically related to "passive" and "passion"). The recognition of virtue in others moves us to desire their good - for their sake. If it were only in the hope of a fair return, the sentiment would not be love as Aristotle defines it.

Aristotle turns now to hatred, which he contrasts sharply with anger:

Anger derives from what happens to oneself, whereas hostility arises also without 
[the offense] being directed at oneself. For if we believe that someone is a certain kind of person, we hate him. Also, anger is always about individuals, for example Callias or Socrates, whereas hatred is also felt toward types: for everyone hates a thief and an informer. Moreover, anger is healed by time, while hatred is incurable. Also, the one is a desire to inflict pain, while the other is a desire to inflict harm: for a person who is angry wishes to perceive [the effects of his revenge], but to the one who hates this is a matter of indifference .... Also, the angry person might feel pity if enough [misfortunes befall the other], but not one who hates: for the former wishes that the person with whom he is angry should suffer in return, but the other wishes that he should cease to exist.

Let us highlight Aristotle's claims in this passage. First, the object of anger is to cause pain to the other, while the object of hatred is to inflict harm. We may wish that people whom we hate should die, but when we are angry, what we desire is that the other person feel hurt in return. In addition, we respond with hatred not only to those who have harmed us in particular, but also to those who have wronged others. Finally, Aristotle affirms that we may feel hatred, but not anger, toward groups or classes. It is one of the fundamental differences between anger and hatred that while the object of anger must be an individual - it is strictly a one-on-one passion - we can hate thieves or informers in general, whether or not they have injured us personally: it is enough that "we believe that someone is a certain kind of person."

Aristotle's view clearly does not conform to the recent inflection of hatred as characterized by "an individual's negative beliefs and feelings about the members of some other group of people because of their race, religious identity, ethnic origin, gender, sexual orientation, age, or disability status" (Levin, 2002, p. 1). There is no motive in Aristotle for hostility toward a given natural class as such. What one dislikes are groups made up of morally corrupt individuals, such as thieves and informers, to cite Aristotle's own examples.

Modern writers almost invariably classify the hostile emotions as "negative," as opposed to ostensibly positive emotions such as love and sympathy. A not untypical judgment by a psychologist has it that "hostility is an abnormal, destructive affect" (Kalogerakis, 2004; cf. Emde, 1980, and the essays collected in Iganski, 2003). Even physiological studies of aggressive violence may conclude that "negative affect can precipitate and accentuate aggressive behavior" (Davidson, Putnam, \& Larson, 2000, p. 591). Where hatred is defended, it is in the tough-guy language of survival of the fittest. Aristotle's analysis is a salutary reminder that there may be people deserving of our antagonism. As the Greek orator Isocrates (15.142) says, hatred toward good people is the sign of a bad character.

Fear

Aristotle's definition of fear (that is, of phobos) runs as follows (Chapter 5):

let fear be a kind of pain or disturbance deriving from an impression of a future evil that is destructive or painful; for not all evils are feared, for example whether one will be unjust or slow, but as many as are productive of great pain or destruction, and these if they are not distant but rather seem near so as to impend. 
For things that are remote are not greatly feared.

In illustration of the last clause, Aristotle points out that all people know they will die, but because death is not near, they do not fear it. It follows from Aristotle's definition of fear, moreover, that frightening things are just those that seem to possess the power to destroy or to inflict the kind of harm that entails intense pain. Note that, although we fear pain, according to Aristotle, it is not pain that is frightening but rather those things that portend it, for example a poisonous snake or a poised spear. The track of a snake in the sand, or a rattling sound, are frightening in turn because they indicate that a snake is nearby. Fear involves knowledge and inference.

Broadly speaking, according to Aristotle, those people are frightening who are unjust or arrogant, who fear us or are our competitors, whom we have wronged or who have wronged us, and indeed anyone who is in a position to do us a bad turn, since, Aristotle says, human beings will usually take advantage of others if they can. The chief catalyst of fear in all these cases is the superior strength of the other party. So too confidence, which Aristotle characterizes as the opposite of fear (it too is an emotion), derives from the knowledge that any rivals we may have are either weak or of a friendly disposition, or else that we have more or stronger allies on our side. Aristotle adds that confidence is inspired also by inference and comparison. Thus, we shall be confident if we believe that we have defeated people who are equal to or stronger than our enemies and rivals, or that we have more wealth, friends, land, and matériel for war than they do. In turn, people are rendered fearful if they are reminded that more powerful people than they have suffered reversals, since this causes them to recognize their own vulnerability. Like anger and hatred, fear, for Aristotle, is not an instinctive aversion but a socially conditioned response in which relations of power and judgments concerning the status and attitudes of others play a crucial role. Aristotle's conception of fear pertains to that same world of intense competition and struggle for dominance that is the context for most of the emotions that he discusses in the Rhetoric.

\section{Shame}

The next emotion that Aristotle treats is shame (Chapter 6). Like many other cultures, classical Greece did not have distinct terms for what we call shame and guilt, and they seem to have made do with one concept where we recognize two. But we must be wary of supposing that the Greek idea either covers both the English shame and guilt or somehow captures only a part of this complex; in particular, one must avoid simple progressivist theories, according to which the ancient Greeks failed to achieve a notion of guilt, which is in turn a sign of the poverty of their moral vocabulary and their incomplete psychological development (I am thinking here of the contrast between "shame cultures" and "guilt cultures," which has its origin precisely in a comparative study of the west and Japan; see Benedict, 1946; Creighton, 1990). As we have seen, however, the ancient Greek emotional lexicon does not map neatly onto modern English concepts. Let us turn, then, to Aristotle's definition of shame (his term is aiskhunê), which runs as follows: "Let shame, then, be a pain or disturbance concerning those ills, either present, past, or future, that are perceived to lead to disgrace, while shamelessness is a disregard or impassivity 
concerning these same things."

Aristotle's inclusion of future ills, along with past or present ills, as causes of shame may seem surprising, since if we feel shame at something still to come it might be supposed that we would avoid the situation or behavior that will induce the emotion. But Aristotle's definition makes it clear that he draws no distinction between prospective or restrictive shame on the one hand, and retrospective or remorseful shame on the other (for a similar inclusiveness in the Chinese conception of shame, see Li, Wang, \& Fischer, 2004). A key element in the definition is the term "perceived" or "imagined." We remember past events, sense present ones, and anticipate future events, and things good or ill may "appear" to us in all three modes. If the ills we perceive or imagine are of the kind that bring about a loss of reputation or disgrace, we respond with the emotion of shame. Of course, such phenomena, if they are memories, can no longer be altered or avoided, save insofar as one can perhaps change the opinions that others hold of them and thus limit the damage to one's status or repute. By contrast, one will ordinarily try to prevent foreseen events of this type from being realized. But envisioning an anticipated ill evokes the emotion of shame just as much as recollecting a past one does, and the very same sentiment that galls us in the case of things that have been done moves us also to avert them, if we can, in the future.

Shame arises not at the contemplation of loss of honor in the abstract, but from specific acts or events which bring about disgrace. Aristotle immediately offers examples of the kinds of ills he has in mind:

If shame is as we have defined it, then it follows that we feel shame for those kinds of ills that seem disgraceful, either for ourselves or those we care about. Such are all those actions that arise out of vice, for example throwing away one's shield or fleeing; for they come from cowardice. Also confiscating a deposit, or wronging someone; for they come from unjustness. And sleeping with the wrong people, or those who are related to the wrong people, or at the wrong time; for they come from sensuality.

Other examples of vices are wrongful gain, illiberality or servility, effeminacy, small-mindedness, meekness and conceitedness, each manifested in visible outward behavior, such as making a profit off the poor, lack of generosity, flattery, lack of endurance, and blowing one's own horn. All these actions are evidence of personal defects, and it is these in turn that, when recognized, lead to a loss of esteem and status. There are thus three elements that together prompt the emotion of shame: a particular act (throwing away one's shield in battle); the fault of character that is revealed by the act (cowardice); and the disgrace or loss of esteem before the community at large.

With this schema, Aristotle seems to bridge the difference that modern investigators suppose exists between shame and guilt, according to which guilt is elicited by a specific act of wrongdoing, while "we feel shame about the very essence of our selves" (Morrison, 1996, p. 12; cf. Gilbert, 1998; Lansky, 1996; Lewis, 1971; Nathanson, 1992). Shame, for Aristotle (and I would say for Greeks in the classical period generally) results from imagining particular acts or events, whether committed or intended, for example doing someone an injustice or failing to help another when it is in one's power to do so. It is 
possible to make amends for such offenses, whether by apologizing or by some other form of compensation. They are limited acts, and do not necessarily entail an annihilation of one's sense of self.

To the causes of shame indicated above, Aristotle adds the condition of not sharing in those advantages which most or all of one's peers enjoy, whether fellow citizens, agemates, or relatives, for example the same level of education or culture. Such a deficiency could be the result of a personal failing, but there might also be other reasons for it. It is doubtless productive of shame to appear boorish in cultivated company, even if it is not one's own fault. Here, then, Aristotle recognizes that shame may arise from circumstances beyond one's control, in contrast to modern guilt, which is commonly taken to presuppose moral responsibility. Nico Frijda (1993, p. 367) reports, however, that despite current theories, his research indicates that while responsibility perhaps pertains to the way we experience guilt, it is not necessarily a component of the antecedent appraisal; that is, one can feel guilty for hitting or narrowly missing a child who jumps in front of one's car without believing one is at fault. The borderline between modern guilt and shame seems fuzzier than one might imagine, and it may well be reasonable, with Aristotle, to see both culpable and morally blameless behaviors as eliciting a single emotion. Aristotle adds, however, that all such defects are the more shameful "if they are perceived to occur on one's own account; for it is all the more a consequence of vice, if one is oneself responsible for what has happened, is happening, or is going to happen." In his discussion of shame, then, Aristotle is not indifferent to the question of accountability. Rather, it figures as an exacerbating condition in relation to those kinds of ills that do not derive from vice or ethical deficiency (for fuller discussion, see Konstan, 2003c).

\section{Gratitude, Pity, and Related Emotions}

We come now to gratitude (Chapter 7), a sentiment that does not typically enter into modern inventories of the emotions. Indeed, if you consult any standard translation of Aristotle's Rhetoric, you will not find gratitude treated there, either, but rather, in the Chapter under consideration, a sentiment translated as "kindness," "benevolence," or the like. I cannot enter here into the technical reasons why this interpretation is incorrect (see Konstan, 2005; also Rapp, 2002). The important point here is that gratitude, like the other emotions we have examined so far, is an emotion that pertains to a world of social relations, in which one's status as benefactor or beneficiary - which is to say, superior or inferior party in a relationship - plays a central role. It is not that gratitude is an objective duty or debt to repay a favor; on the contrary, Aristotle defines a favor as "a service to one who needs it, not in return for anything, nor so that the one who performs the service may gain something, but so that the other may." As an emotion, gratitude depends on an awareness of relative social positions, but being grateful was not "regarded as a duty" (contrast Westermarck, 1908, p. 154). It was a response to the receipt of a benefit that had been bestowed precisely with no ulterior intention of gain on the benefactor's part.

Four more emotions fill out Aristotle's inventory, all of them relatively marginal to modern European and American studies of the emotions. These are pity (Chapter 8), which almost never enters into lists of emotion today, perhaps because it is considered too 
close to contempt; envy (Chapter 9), an emotion that is often denied in democratic societies; indignation (Chapter 10); and finally competitiveness (Chapter 11), the last two scarcely classified these days as emotions at all. Rather than enter into a discussion of these emotions in detail, I provide a brief review of Aristotle's definitions, before drawing some conclusions about how Aristotle conceived of the nature and function of emotions in general, what kind of world they seem to pertain to, and, finally, what the implications of his discussion may be for the comparative psychology of the emotions.

Aristotle defines pity, then, as "a kind of pain in the case of an apparent destructive or painful harm in one not deserving to encounter it," and which, he adds, "one might expect oneself, or one of one's own, to suffer, and this when it seems near." Pity depends on one's own vulnerability to the harm suffered by another: it is not an emotion of identification, like the modern empathy, but one depending on an inference about one's exposure to misfortune. This is why Aristotle concludes that neither those who have never suffered a reversal - that is, the exceptionally privileged - nor those who are at the nadir of their fortunes, are prone to feeling pity, since neither expects to suffer something worse: those least well off believe they have already endured the worst. In addition, one does not feel pity, Aristotle says, for those nearest to us, for example, a child or parent: in this case, rather, we feel the harm as though it had befallen ourselves. True, Aristotle mentions, in his definition of pity, one's own near and dear ones, but not among those who elicit pity when they suffer, but rather among the conditions of our own vulnerability. It is worth noting that, on Aristotle's account, the gods would be immune to pity: mercy is not a major attribute of the ancient Greek deities (for a full discussion of pity in classical antiquity, see Konstan, 2001).

When he comes to envy and indignation, Aristotle offers an interesting critique of what he considers an erroneous view. Indignation, he says, is "feeling pain at someone who appears to be succeeding undeservedly." So understood, it is, Aristotle says, the opposite of pity, which is pain felt at another's undeserved misfortune. Aristotle goes on to note, however, that according to some, not indignation but envy (Aristotle's word is phthonos) is the opposite of pity, on the grounds that envy is "a disturbing pain arising from the well-being" of another. But this, Aristotle says, is not correct. For envy, he goes on to specify, is "a kind of pain, in respect to one's equals, for their apparent success in things called good, not so as to have the thing oneself but [solely] on their account" - that is, because they have a good that we do not, irrespective of its use to us. It arises not because the other person is undeserving, but simply because he is our equal or similar. Unlike indignation, envy does not take account of merit or desert, and this is why it is not suited to a decent person. Rather, it is characteristic of what Aristotle describes as a smallminded concern for image. Finally, Aristotle describes a more positive version of envy, which we may render something like "competitiveness" - Aristotle's term is zêlos, from which are derived the English words "zeal" and also "jealousy" (cf. Italian gelosia, French jalousie, etc.). This emotion is also triggered by the perception that one's equals are faring better than oneself, but it inspires in us not the malicious desire that the other do worse, but rather the perfectly healthy ambition to improve our position and achieve what the other has acquired. 


\section{CONCLUSION}

For Aristotle, the emotions are, in general, responses to the behavior and intentions of others. In this respect, they are deeply embedded in social life. We are not angry with stones, we do not pity or envy or compete emulously with inanimate objects; neither are we ashamed before them; nor do we owe them gratitude. We cannot love or hate them (they are not bearers of vices, after all), nor do we really fear them in the strict sense of the term: they intend us no harm, and we do not usually calculate our relative position of strength in regard to them. Emotions are about people.

The Greek emotions are specific to Greek society and to societies similar to that of the Greeks, that is, relatively democratic societies in which social standing and ideas of honor nevertheless play a central role (cf. Elster, 1999, p. 75). But cultures have blind spots: if we can perceive better than Aristotle himself some of the ways in which the emotions he describes form a coherent group, attention to classical Greek ideas of the emotions may illuminate some aspects of our own emotional concepts. Thus, it is only recently that psychologists have begun to investigate the emotions as specifically social phenomena, that is, responses to intentional acts, along with the effects of emotion on belief, which was central to Aristotle's definition of an emotion or pathos.

Finally, a word about the treatment of emotions or emotional disorders (cf. Nussbaum, 1994). Aristotle was, of course, concerned with stimulating or abating emotions in ordinary people; his treatise concerns rhetoric, not mental health. But there are signficant consequences for psychology in his approach, I believe, and they are worth a moment's consideration. Let me approach the question from a different and perhaps surprising angle. For Aristotle, as for many thinkers of his time, animals did not have emotions. Why not? I quote a recent essay by William Fortenbaugh, who has contributed importantly to our understanding of Aristotle's conception of the emotions (2002, p. 94): "Humans have the capacity to think and therefore can believe that an insult has occurred and that some danger threatens. Animals lack this cognitive capacity and therefore cannot experience emotions as analyzed by Aristotle." This may seem heartless, but we may get a better sense of Aristotle's intention, and also that of the philosophers who followed him such as the Stoics and Epicureans, who shared his view, if we consider the question of animal emotions from a therapeutic perspective. In order to change emotional responses or habits, according to the ancient thinkers, it was necessary to alter beliefs: to make someone angry, or eliminate anger, one addressed beliefs about the intention that lay behind an apparent slight (was it deliberate? was it out of place?); to affect the emotions of pity and indignation, one discussed whether it was merited or not; to manipulate fear in another, one analyzed the relative power of one's antagonists; and so forth. Raw, instinctive feelings, such as sudden surprise or disgust, which so often figure in modern catalogues, were irrelevant on this view: noticing a bad smell or starting at a loud noise did not count as an emotion but at best as a "pre-emotion," as the Stoics called this kind of automatic response. Now, the Greeks could recognize the quivering terror of an animal as well as we can; but they did not imagine that they could talk it out of its anxiety by convincing it that the fear was empty, say by explaining that a noble death was not a bad 
thing (think of Socrates' defense speech called the Apology, as imaginatively recreated by Plato). The emotions were consequences of beliefs, and in turn made us susceptible to certain kinds of beliefs, as Aristotle makes clear. Today, we often imagine that the proper response to anger is self-control, or taking a deep breath until it passes. Aristotle would have inquired, first and foremost, whether the anger was justified, which is to say, whether the events that had elicited it were properly interpreted. And this, it seems to me (as an interloper into the field of psychology), may still have something useful to teach us in this day and age.

\section{REFERENCES}

Abu-Lughod, L. 1999 (orig. 1986). Veiled sentiments: Honor and poetry in a Bedouin society. Berkeley: University of California Press.

Allen, D. 1999. Democratic dis-ease: Of anger and the troubling nature of punishment. In S. A. Bandes (Ed.), The passions of law (pp. 191-214). New York: New York University Press.

Averill, J. R. 1980. A Constructivist view of emotion. In R. Plutchik \& H. Kellerman (Eds.), Theories of emotion (pp. 305-340). New York: Academic Press.

Barton, C. A. 2001. Roman honor: The fire in the bones. Berkeley: University of California Press.

Bavelas, J. B., \& Chovil, N. 1997. Faces in dialogue. In J. A. Russell \& J. M. Fernández-Dols (Eds.), The Psychology of facial expression (pp. 334-346). Cambridge: Cambridge University Press.

Benedict, R. 1946. The chrysanthemum and the sword: Patterns of Japanese culture. Boston: Houghton Mifflin.

Ben-Ze'ev, A. 2000. The subtlety of emotions. Cambridge MA: MIT Press.

Braund, S., \& Most, G. W. (Eds.). 2003. Ancient anger: Perspectives from Homer to Galen. Yale Classical Studies, 32. Cambridge: Cambridge University Press.

Buss, D. M. 1994. The evolution of desire: Strategies of human mating. New York: BasicsBooks.

Buss, D. M. 2000. The dangerous passion: Why jealousy is as necessary as love and sex. New York: The Free Press.

Cairns, D. L. 1993. Aidôs: The psychology and ethics of honour and shame in ancient Greek literature. Oxford: The Clarendon Press.

Casimire, M. J., \& Schnegg, M. 2003. Shame across cultures: The evolution, ontogeny, and function of a 'moral emotion.' In H. Keller, Y. H. Poortinga, \& A. Scholmerich (Eds.), Between culture and biology: Perspectives on ontogenetic development (pp. 270-302). Cambridge: Cambridge University Press.

Creighton, M. R. 1990. Revisiting shame and guilt cultures: A forty-year pilgrimage. Ethos, 18, 279-307.

Darwin, C. 1998 (orig. 1872). The expression of the emotions in man and animals (3rd ed., with Introduction, Afterword and Commentary by P. Ekman). London: HarperCollins.

Davidson, R. J., Putnam, K. M., \& Larson, C. L. 2000. Dysfunction in the neural circuitry of emotion regulation: A possible prelude to violence. Science, 289, 591-594.

Dover, K. 1994 (orig. 1974). Greek popular morality in the time of Plato and Aristotle (Rev. ed.). Indianapolis: Hackett Publishing Company.

Ekman, P. 1980. The face of man: Expressions of universal emotions in a New Guinea village. New York: Garland.

Ekman, P. 1998. Afterword. In C. Darwin, The expression of the emotions in man and animals (3rd ed., with Introduction, Afterword and Commentary by P. Ekman, pp. 363-393). London: HarperCollins.

Elster, J. 1999. Alchemies of the mind: Rationality and the emotions. Cambridge: Cambridge University Press.

Emde, R. N. 1980. Toward a psychoanalytic theory of affect: I. The organizational model and its propositions. In S. I. Greenspan \& G. H. Pollock (Eds.), The course of life: Psychoanalytic contributions towards understanding personality development (pp. 66-83). Madison Ct: Int. Univ. 
Press.

Farrell, D. M. 1989. Of jealousy and envy. In G. Graham \& H. LaFollett (Eds.), Person to person (pp. 245268). Philadelphia: Temple University Press.

Forgas, J. P. 2000. Feeling is believing? The role of processing strategies in mediating affective influences on beliefs. In N. H. Frijda, A. S. R. Manstead, \& S. Bem (Eds.), Emotions and beliefs: how feelings influence thoughts (pp. 108-143). Cambridge: Cambridge University Press.

Fortenbaugh, W. W. 2002 (orig. 1975). Aristotle on emotion (2nd ed.). London: Duckworth.

Frank, R. H. 1988. Passions within reason: The strategic role of the emotions. New York: W.W. Norton.

Frijda, N. H. 1993. The place of appraisal in emotion. Cognition and Emotion, 7, 357-387.

Frijda, N. H., Manstead, A. S. R., \& Bem, S. (Eds.). 2000. Emotions and beliefs: How feelings influence thoughts. Cambridge: Cambridge University Press.

Gilbert, P. 1998. What is Shame? Some Core Issues and Controversies. In P. Gilbert \& B. Andrews (Eds.), Shame: Interpersonal behavior, psychopathology, and culture (pp. 3-38). New York: Oxford University Press.

Harré, R. (Ed.). 1986. The Social construction of emotions. Oxford: Basil Blackwell.

Harris, W. V. 2001. Restraining rage: The ideology of anger control in classical antiquity. Cambridge MA: Harvard University Press.

Hatfield, E., \& Rapson, R. L. 2000. Love and attachment process. In M. Lewis \& J. M. Haviland-Jones (Eds.), Handbook of emotions (2nd ed., pp. 654-662). New York: The Guilford Press.

Hinton, A. L. 1999. Introduction: Developing a biocultural approach to the emotions. In A. L. Hinton (Ed.), Biocultural approaches to the emotions (pp. 1-37). Cambridge: Cambridge University Press.

Iganski, P. (Ed.). 2003. The hate debate: Should hate be punished as a crime? London: Profile Books.

Kalogerakis, M. G. 2004. Hostility in adolescents: Genesis, evolution and therapeutic challenge. Adolescent Psychiatry, 28, 1-5 (on line at http://www.findarticles.com/p/articles/mi_qa3882/is_200401/ ai_n9383795).

Kaster, R. A. 1997. The shame of the Romans. Transactions of the American Philological Association, 127, $1-19$.

Kaster, R. A. 2005. Emotion, restraint, and community in ancient Rome. New York: Oxford University Press.

Kennedy, G. A. (Trans. \& Ed.). 1991. Aristotle on rhetoric: A theory of civic discourse. New York: Oxford University Press.

Konstan, D. 2001. Pity transformed. London: Duckworth.

Konstan, D. 2003a. Before jealousy. In D. Konstan \& N. K. Rutter (Eds.), Envy, spite, and jealousy: The rivalrous emotions in ancient Greece (pp. 7-27). Edinburgh: Edinburgh University Press.

Konstan, D. 2003b. Praotês as an emotion in Aristotle's Rhetoric. Hyperboreus, 9, 318-329.

Konstan, D. 2003c. Shame in ancient Greek. Social Research, 70, 601-630.

Konstan, D. 2005. The emotion in Aristotle Rhetoric 2.7: Gratitude, not kindness. In D. Mirhady (Ed.), The influences on Aristotle's Rhetoric. New Brunswick, NJ: Transaction Publishers. (Rutgers University Studies in Classical Humanities 12.)

Konstan, D. 2006. The emotions of the ancient Greeks: Studies in Aristotle and classical literature. Toronto: University of Toronto Press.

Konstan, D., \& Rutter, N. K. (Eds.). 2003. Envy, spite, and jealousy: The rivalrous emotions in ancient Greece. Edinburgh: Edinburgh University Press.

Lansky, M. R. 1996. Shame and suicide in Sophocles' Ajax. Psychoanalytic Quarterly, 65, 761-786.

Lazarus, R. S. 1991. Emotion and adaptation. New York: Oxford University Press.

Lazarus, R. S. 2001. Relational meaning and discrete emotions. In K. R. Scherer, A. Schorr, \& T. Johnstone (Eds.), Appraisal processes in emotion: Theory, methods, research (pp. 37-67). Oxford: Oxford University Press.

Levin, J. 2002. The violence of hate: Confronting racism, anti-Semitism, and other forms of bigotry. Boston: Allyn and Bacon.

Lewis, H. B. 1971. Shame and guilt in neurosis. New York: International Universities Press.

Li, J., Wang, L., \& Fischer, K. W. 2004. The organization of Chinese shame concepts. Cognition and emotion, 18, 767-797.

Lutz, C. A. 1988. Unnatural emotions: Everyday sentiments on a micronesian atoll and their challenge to 
Western theory. Chicago: University of Chicago Press.

Lyons, W. 1980. Emotion. Cambridge: Cambridge University Press.

Morrison, A. P. 1996. The culture of shame. New York: Ballantine Books.

Nathanson, D. L. 1992. Shame and pride: Affect, sex, and the birth of the self. New York: W.W. Norton.

Nelson, C. A., \& de Haan, M. 1997. A neurobiological approach to the recognition of facial expressions in infancy. In J. A. Russell \& J. M. Fernández-Dols (Eds.), The psychology of facial expression (pp. 176204). Cambridge: Cambridge University Press.

Nussbaum, M. C. 1994. The therapy of desire: Theory and practice in Hellenistic ethics. Princeton: Princeton University Press.

Nussbaum, M. C. 2001. Upheavals of thought: The intelligence of emotions. Cambridge: Cambridge University Press.

Oatley, K. 1992. Best laid schemes: The psychology of emotions. Cambridge: Cambridge University Press and Paris: Editions de la Maison des Sciences de l'Homme.

Rapp, C. (Trans. and Ed.). 2002. Aristoteles Rhetorik. Berlin: Akademie Verlag.

Roberts, W. R. (Trans.) 1984. Rhetoric. In Barnes, J. (Ed.), The complete works of Aristotle (Vol. 2, pp. 2152-2269). Princeton: Princeton University Press (Bollingen Series 71.2).

Rorty, A. O. (Ed.). 1980. Explaining emotions. Berkeley: University of California Press.

Rorty, A. O. (Ed.). 1996. Essays on Aristotle's Rhetoric. Berkeley: University of California Press.

Rosenwein, B. H. (Ed.). 1998. Anger's past: The social uses of an emotion in the middle ages. Ithaca: Cornell University Press.

Russell, J. A. 1997. Reading emotions from and into faces: Resurrecting a dimensional-contextual perspective. In J. A. Russell \& J. M. Fernández-Dols (Eds.), The psychology of facial expression (pp. 295-320). Cambridge: Cambridge University Press.

Scherer, K. R., Schorr, A., \& Johnstone, T. (Eds.). 2001. Appraisal processes in emotion: Theory, methods, research. Oxford: Oxford University Press.

Solomon, R. C. 1993. The passions: Emotions and the meaning of life (Rev. ed.). Indianapolis: Hackett Publishing Co.

Sorabji, R. 2000. Emotion and peace of mind: From stoic agitation to Christian temptation. Oxford: Oxford University Press.

Tavris, C. 1989. Anger: The misunderstood emotion (Rev. ed.). New York: Simon and Schuster.

Toohey, P. 2004. Melancholy, love, and time: Boundaries of the self in ancient literature. Ann Arbor: University of Michigan Press.

Webster's New International Dictionary of the English Language. 1961. (2nd ed.). Springfield, Mass.: G. and C. Merriam.

Westermarck, E. 1908. The origin and development of the moral ideas (Vol. 2). London: MacMillan.

Wierzbicka, A. 1999. Emotions across languages and cultures: Diversity and universals. Cambridge: Cambridge University Press. 